\title{
Human milk intake in preterm infants and neurodevelopment at 18 months corrected age
}

\author{
Talia Jacobi-Polishook', Carmel T. Collins ${ }^{2-4}$, Thomas R. Sullivan ${ }^{5}$, Karen Simmer ${ }^{6}$, Matthew W. Gillman7, Robert A. Gibson ${ }^{2,3,8}$, \\ Maria Makrides ${ }^{2-4}$ and Mandy B. Belfort ${ }^{1,9}$
}

BACKGROUND: The effect of human milk intake on neurodevelopment in preterm infants is uncertain.

METHODS: We analyzed data from 611 participants in the DHA for Improvement of Neurodevelopmental Outcomes study, enrolled at $\leq 33$ wk gestation from five Australian perinatal centers. The main exposures were (i) average daily human milk intake during the neonatal hospitalization and (ii) total duration of human milk intake before and after discharge. Outcomes were Bayley Scales of Infant Development, 2nd Edition Mental (MDI), and Psychomotor (PDI) Development Indexes.

RESULTS: Adjusting for confounders in linear regression, human milk intake was not associated with higher MDI (0.2 points per $25 \mathrm{ml} / \mathrm{kg} / \mathrm{d}$; $95 \%$ confidence interval $(\mathrm{Cl})$ : $-0.6,1.0)$ or PDI (-0.3 points; $95 \% \mathrm{Cl}:-1.1,0.4)$. Longer duration of human milk intake was also not associated with $\mathrm{MDI}$ (0.1 points per month; $95 \% \mathrm{Cl}:-0.2,0.3)$ or PDI (-0.2 points per month; $95 \%$ $\mathrm{Cl}:-0.5,0.01)$ scores, except in infants born 29-33 wk gestation $(n=364, \mathrm{MDI} 0.3$ points higher per additional month, 95\% Cl: $0.1,0.6)$.

CONCLUSIONS: We found no associations of human milk intake during the neonatal hospitalization with neurodevelopment at 18 mo corrected age.

$\mathbf{P}$ reterm infants are at high risk for neurodevelopmental impairments later in life $(1,2)$, and few strategies (3-5) either before or after neonatal hospital discharge have proven effective in improving these outcomes. Promoting greater human milk intake has promise, as many observational studies (6-10) in full-term cohorts have identified positive associations of breastfeeding with later cognitive outcomes. Further, results of a large, cluster randomized trial suggest that the link observed in healthy populations between breastfeeding and cognitive development may be causal (11).
Because preterm infants have different nutritional needs from full-term infants (12), results from studies of full-term populations may not generalize to preterm infants. Some studies in contemporary preterm cohorts have found positive associations of human milk intake with neurodevelopment (13-15), while others were largely null (16-18). A recent meta-analysis (19) identified several methodologic limitations of prior studies that may account for these inconsistent findings, including a lack of data on the dose and duration of human milk intake and the potential for residual confounding, particularly by neonatal complications and socio-demographic variables.

The aim of this study was to examine associations of human milk intake with neurodevelopment at 18 mo corrected age (age from term equivalent) in infants born $\leq 33$ wk gestation. We hypothesized that greater dose of human milk intake during the neonatal hospitalization and longer duration of human milk intake (including the period after neonatal discharge) would be associated with better outcomes; and that associations would be stronger in infants more vulnerable to neurodevelopmental impairment, including infants born small for gestational age (SGA) and lower gestational age infants. We also hypothesized a stronger association in female infants vs. males because docosahexaenoic acid (DHA), a key nutrient in human milk, appears to confer a greater neurodevelopmental benefit to females than males (20).

\section{RESULTS}

Characteristics of study participants are shown in Table 1 overall and according to quartile of human milk intake during the neonatal hospitalization. Table 2 describes human milk intake and Bayley Scales of Infant Development, 2nd Edition (Bayley-II) scores at 18 mo corrected age for the study cohort. Average human milk intake during the hospitalization was moderately correlated with total duration of human milk intake (Spearman $r=0.53$ ).

\footnotetext{
'Division of Newborn Medicine, Boston Children's Hospital, Boston, Massachusetts; ${ }^{2}$ Women's and Children's Health Research Institute, Adelaide, Australia; ${ }^{3}$ Healthy Mothers, Babies and Children, South Australian Health and Medical Research Institute, Adelaide, Australia; ${ }^{4}$ School of Pediatrics and Reproductive Health, The University of Adelaide, Adelaide, Australia; ${ }^{5}$ School of Population Health, The University of Adelaide, Adelaide, Australia; ${ }^{6}$ Centre for Neonatal Research and Education, School of Paediatrics and Child Health, University of Western Australia, Perth, Australia; ${ }^{7}$ Obesity Prevention Program, Department of Population Medicine, Harvard Medical School/Harvard Pilgrim Health Care Institute, Boston, Massachusetts; ${ }^{8}$ School of Agriculture, Food, and Wine, The University of Adelaide, Adelaide, Australia; ${ }^{9}$ Department of Pediatric Newborn Medicine, Brigham and Women's Hospital, Boston Massachusetts. Correspondence: Mandy B. Belfort (mbrown9@partners.org)

Received 9 March 2016; accepted 17 March 2016; advance online publication 29 June 2016. doi:1 0.1038/pr.2016.114
} 
Table 1. Characteristics of 611 study participants, parents, and households

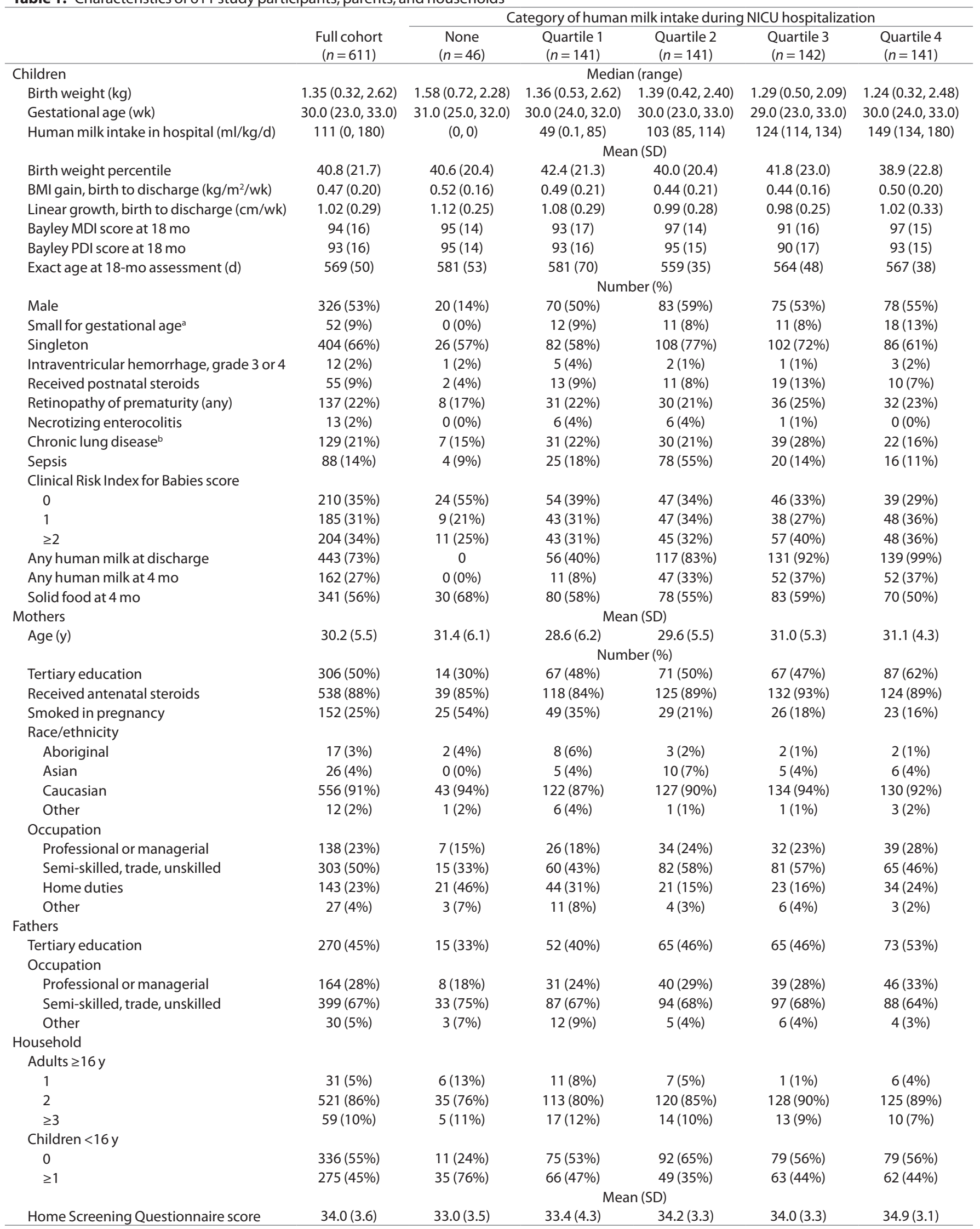




\section{Articles | Jacobi-Polishook et al.}

Table 3 shows associations of human milk intake during the neonatal hospitalization with Bayley-II scores at $18 \mathrm{mo}$ corrected age. Models adjusted only for the infant's age at assessment (Model 0) and additionally adjusted for potential confounders (Model 1) yielded similar results. In Model 1, for each additional $25 \mathrm{ml} / \mathrm{kg} / \mathrm{d}$ of human milk the Mental Development Index (MDI) score was 0.2 points higher $(95 \%$ confidence interval (CI): $-0.6,1.0)$ and the Psychomotor Development Index (PDI) was 0.3 points lower (95\% CI: -1.1 , 0.4). Further adjustment for BMI gain from birth to discharge (Model 2) minimally changed estimates, and additional adjustment for linear growth had no effect (not shown). Figure 1 shows estimated mean Bayley-II scores by quartile of human milk intake in the neonatal hospitalization, with no trend evident in MDI or PDI scores across quartiles, nor any clear indication of nonlinear associations.

Stratifying by SGA status (adjusting for age only given the small number of SGA infants) and by gestational age, sex (Table 3), and DHA status revealed no substantial differences in the magnitude of associations between strata.

Associations of the total duration of human milk intake with Bayley-II scores are shown in Table 4. In the full cohort, associations with MDI and PDI were null. In infants with gestational age $29-33 \mathrm{wk}$, the MDI score was 0.3 points higher per additional month of human milk intake (95\% CI: 0.1, 0.6; interaction $P=0.3$ ), whereas for infants $<29 \mathrm{wk}$ gestation, the PDI score was 0.5 points lower per month (95\% CI: $-1.0,-0.03$; interaction $P=0.06)$. The PDI score was also lower for infants born SGA (1.0 point lower per month, 95\% CI: $-2.1,-0.0)$. No substantial differences were seen in analyses stratified by sex or by DHA status (interaction $P=0.98$ for MDI and 0.28 for PDI).

\section{DISCUSSION}

In this study of over 600 preterm infants $\leq 33$ wk gestation, we did not find statistically or clinically significant associations of the volume of human milk intake during the neonatal hospitalization or the total duration of human milk intake with neurodevelopmental outcomes at 18 mo corrected age.

Our main results diverge from another large $(n=1,035)$ cohort study (13) of extremely-low-birth-weight $(<1,000 \mathrm{~g})$ US infants in the Neonatal Research Network, which found that for every $25 \mathrm{ml} / \mathrm{kg} / \mathrm{d}$ human milk intake during the neonatal hospitalization, the MDI and PDI scores at 18 mo corrected age were $\sim 1.3$ and $\sim 1.6$ points higher, respectively. Those point estimates are substantially larger than ours ( $0.2 \mathrm{MDI}$ and -0.3 PDI points per $25 \mathrm{ml} / \mathrm{kg} / \mathrm{d}$ ). The Vohr study included only extremely-low-birth-weight infants, whereas ours included heavier and more mature infants. However, our analysis of 138 infants $<29$ wk gestation was null for MDI, and revealed a small, negative association of human milk intake with PDI, suggesting that differences in gestational age do not explain our discrepant results. Although Vohr adjusted for several sociodemographic variables, that US cohort was substantially more diverse in race, ethnicity, education, and marital status as compared with our more homogeneous Australian cohort, raising the possibility that residual confounding explains the Vohr
Table 2. Measures of human milk intake and Bayley-II scores at 18 mo corrected age $(n=611)$

\begin{tabular}{|c|c|}
\hline Human milk intake & $\begin{array}{c}\text { Median } \\
\text { (interquartile } \\
\text { range) }\end{array}$ \\
\hline During the neonatal hospitalization $(\mathrm{ml} / \mathrm{kg} / \mathrm{d})$ & $111(71,132)$ \\
\hline \multirow[t]{2}{*}{ Total duration (mo) } & $3.2(1.5,7.6)$ \\
\hline & Number (\%) \\
\hline Received any human milk & $565(93 \%)$ \\
\hline \multicolumn{2}{|l|}{ Human milk status at hospital discharge } \\
\hline Formula only & $167(27 \%)$ \\
\hline Mixed breast milk and formula & $121(20 \%)$ \\
\hline Breast milk only & $322(53 \%)$ \\
\hline \multicolumn{2}{|l|}{ Human milk status at $4 \mathrm{mo}$} \\
\hline Formula only & $444(73 \%)$ \\
\hline Mixed breast milk and formula & $63(10 \%)$ \\
\hline Breast milk only & $99(16 \%)$ \\
\hline Any human milk at 12 mo & $52(9 \%)$ \\
\hline Any human milk at $18 \mathrm{mo}$ & $18(3 \%)$ \\
\hline Bayley-II scores & Mean (SD) \\
\hline Mental Development Index & $94.5(15.6)$ \\
\hline Psychomotor Development Index & $93.1(15.7)$ \\
\hline
\end{tabular}

Bayley-II, Bayley Scales of Infant Development, 2nd Edition.

study's positive results. Consistent with Vohr, another study (14) of preterm infants $<32 \mathrm{wk}$ gestation identified a positive, linear trend in mental processing scores at $5 \mathrm{y}$ of age according to duration of breastfeeding, categorized as: no mother's milk; mother's milk during hospitalization only; weaned $<2$ mo after discharge; weaned at or after 2 mo. It is possible that developmental assessment at $18 \mathrm{mo}$ - as in our study-is too early to detect subtle effects of human milk on higher order cognitive processes better reflected in school age outcomes.

Our null results are consistent with other studies of human milk intake by preterm infants during the neonatal hospitalization, including one (17) that found no association of human milk intake through $4 \mathrm{wk}$ of life with Bayley-II scores at $20 \mathrm{mo}$ (reported estimate equivalent to $-0.3 \mathrm{MDI}$ points per $25 \mathrm{ml} / \mathrm{kg} / \mathrm{d})$. That study was limited by its small sample size $(n=96)$, evident in its relatively wide CIs. Our CIs $(-0.6,1.0$ MDI points per $25 \mathrm{ml} / \mathrm{kg} / \mathrm{d}$ ) exclude most clinically important effects, although the possibility remains of small benefits with population-level importance (21). Another study (18) that reported null results was limited by the use of a dichotomous exposure variable (predominant breast milk vs. predominant formula), which has the potential to underestimate true associations, whereas we examined human milk intake over a wide range. An international study (16) by O'Connor also found no associations of human milk intake with Bayley scores at 12 mo corrected age.

Very few studies have examined human milk intake beyond hospital discharge with respect to neurodevelopment in preterm infants. A population-based cohort of 745 infants born 
Table 3. Associations of human milk intake during the neonatal hospitalization with Bayley-II scores at 18 mo corrected age

\begin{tabular}{|c|c|c|}
\hline & \multicolumn{2}{|c|}{$\begin{array}{l}\text { Points per } 25 \mathrm{ml} / \mathrm{kg} / \mathrm{d} \text { of human } \\
\text { milk }(95 \% \mathrm{Cl})\end{array}$} \\
\hline & $\begin{array}{c}\text { Mental } \\
\text { Development } \\
\text { Index }\end{array}$ & $\begin{array}{l}\text { Psychomotor } \\
\text { Development } \\
\text { Index }\end{array}$ \\
\hline \multicolumn{3}{|l|}{ Full cohort } \\
\hline Model 0: Adjusted for child age & $\begin{array}{c}0.5(-0.2,1.2) \\
n=611\end{array}$ & $\begin{array}{c}-0.2(-0.9,0.4) \\
n=609\end{array}$ \\
\hline Model 1: Model $0+$ confounders $^{\mathrm{a}}$ & $\begin{array}{c}0.2(-0.6,1.0) \\
n=552\end{array}$ & $\begin{array}{c}-0.3(-1.1,0.4) \\
n=550\end{array}$ \\
\hline Model 2: Model 1 + BMl gain ${ }^{b}$ & $\begin{array}{c}0.5(-0.5,1.4) \\
n=406\end{array}$ & $\begin{array}{c}-0.7(-1.6,0.2) \\
n=404\end{array}$ \\
\hline \multicolumn{3}{|l|}{ Stratified by fetal growth status (Model 0 ) } \\
\hline Not small for gestational age & $\begin{array}{c}0.5(-0.2,1.2) \\
n=559\end{array}$ & $\begin{array}{c}-0.3(-1.0,0.4) \\
n=557\end{array}$ \\
\hline Small for gestational age & $\begin{array}{c}0.5(-2.2,3.2) \\
n=52\end{array}$ & $\begin{array}{c}1.0(-2.1,4.1) \\
n=51\end{array}$ \\
\hline \multicolumn{3}{|l|}{ Stratified by gestational age (Model 1) } \\
\hline Gestational age 29-33 wk & $\begin{array}{c}0.5(-0.4,1.4) \\
n=364\end{array}$ & $\begin{array}{c}0.1(-0.8,1.1) \\
n=363\end{array}$ \\
\hline Gestational age $<29$ wk & $\begin{array}{c}-0.7(-2.1,0.6) \\
n=188\end{array}$ & $\begin{array}{c}-1.2(-2.4,0.03) \\
n=187\end{array}$ \\
\hline \multicolumn{3}{|l|}{ Stratified by sex (Model 1) } \\
\hline Female & $\begin{array}{c}0.2(-1.0,1.3) \\
n=258\end{array}$ & $\begin{array}{c}-0.03(-1.1,1.0) \\
n=256\end{array}$ \\
\hline Male & $\begin{array}{c}-0.3(-0.7,1.3) \\
n=294\end{array}$ & $\begin{array}{c}-0.3(-1.3,0.7) \\
n=294\end{array}$ \\
\hline \multicolumn{3}{|l|}{ Stratified by DHA status (Model 1) } \\
\hline Standard & $\begin{array}{c}0.2(-0.9,1.2) \\
n=284\end{array}$ & $\begin{array}{c}-0.8(-1.8,0.2) \\
n=283\end{array}$ \\
\hline High & $\begin{array}{c}0.1(-1.0,1.2) \\
n=268\end{array}$ & $\begin{array}{c}0.3(-0.8,1.4) \\
n=267\end{array}$ \\
\hline
\end{tabular}

Bayley-II, Bayley Scales of Infant Development, 2nd Edition; DHA, docosahexaenoic acid. airth weight percentile, gestational age, sex, plurality, chronic lung disease, necrotizing enterocolitis, antenatal steroids, sepsis, postnatal steroids, Clinical Risk Index for Babies score, intraventricular hemorrhage grade 3 or 4 , retinopathy of prematurity, maternal age, maternal and paternal education, maternal smoking during pregnancy, number of children and adults living at home, maternal and paternal occupation, and Home Screening Questionnaire score. ${ }^{\mathrm{b}} \mathrm{C}$ hange in $\mathrm{BMl}\left(\mathrm{kg} / \mathrm{m}^{2}\right)$ from birth to hospital discharge.

at $<37 \mathrm{wk}$ gestation found that more prolonged breastfeeding appeared beneficial, for example, breastfeeding $\leq 2$ mo vs. none was associated with a 4-point higher score on a test of picture similarities at school age (15). Half of the infants in that cohort were never admitted to a special care nursery, suggesting they were relatively healthy, whereas infants in our cohort were all born $\leq 33 \mathrm{wk}$ and required admission to neonatal intensive care. We found a positive association (0.3 MDI points per month of human milk intake) only in our more mature infants (29-33wk gestation), which also suggests that continued human milk feeding may be particularly beneficial for healthier, more mature preterm infants. However, there was no statistically significant interaction and it is possible that this was a chance finding. a

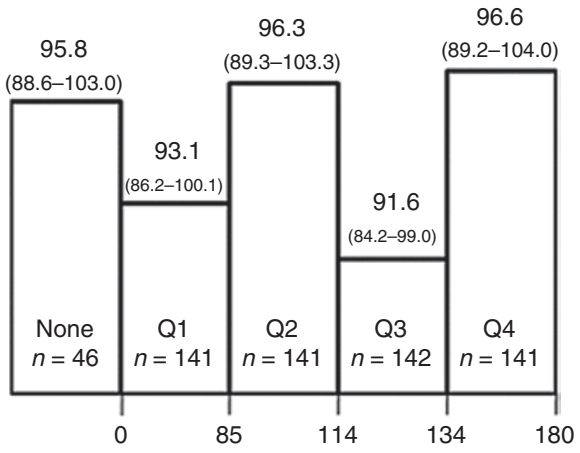

b

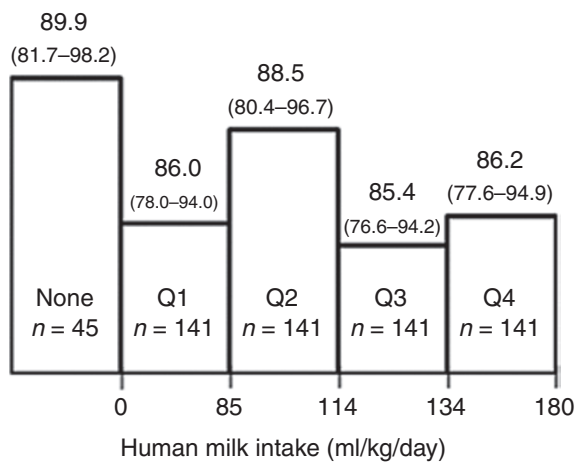

Figure 1. Estimated mean scores on the Bayley Scales of Infant Development, 2 nd edition (95\% confidence interval) in each quartile of human milk intake during the neonatal hospitalization. (a) The Mental Development Index (MDI) and (b) the Psychomotor Development Index (PDI). Estimates are adjusted for age, birth weight percentile, gestational age, sex, plurality, chronic lung disease, necrotizing enterocolitis, antenatal steroids, sepsis, postnatal steroids, Clinical Risk Index for Babies score, intraventricular hemorrhage grade 3 or 4, retinopathy of prematurity, maternal age, maternal and paternal education, mother smoking status during pregnancy, number of children and adults living at home, maternal and paternal occupation, and Home Screening Questionnaire score. Trend $P$ values are 0.66 for $\mathrm{MDI}$ and 0.30 for PDI.

It is notable that evidence is inconsistent regarding benefits of human milk intake during the neonatal hospitalization on neurodevelopment in preterm infants, whereas both observational $(6,7,10,22)$ and interventional (11) studies in healthy, full-term populations have been more consistent in showing a benefit. While human milk evolved to provide optimal nutrition for full-term infants, preterm infants have different nutritional needs (12), which is why fortification of human milk is routine practice in most neonatal units. Further, the developmental timing of human milk exposure for a preterm infant during the neonatal hospitalization differs substantially from a full-term infant after birth. Major fetal brain growth and structural development occur during the last trimester of pregnancy. For preterm infants, these developmental processes occur during the neonatal hospitalization (23) and may be particularly sensitive to the nutritional environment. In our study, we explored the role of poor growth-which itself is associated with neurodevelopmental impairment (24) - by adjusting analyses for BMI gain and linear growth during the neonatal hospitalization. This adjustment did not change estimates, but these measures are limited as proxies for specific nutritional deficiencies. Unfortunately, we did not analyze human milk 
Table 4. Adjusted associations of total duration of human milk intake with Bayley-II scores at 18 mo corrected age

\begin{tabular}{|c|c|c|}
\hline & \multicolumn{2}{|c|}{$\begin{array}{l}\text { Points per month of human milk intake } \\
\text { (95\% confidence interval) }\end{array}$} \\
\hline & $\begin{array}{l}\text { Mental } \\
\text { Development } \\
\text { Index }\end{array}$ & $\begin{array}{l}\text { Psychomotor } \\
\text { Development } \\
\text { Index }\end{array}$ \\
\hline Full cohort ${ }^{a}$ & $\begin{array}{c}0.1(-0.2,0.3) \\
n=529\end{array}$ & $\begin{array}{c}-0.2(-0.5,0.0) \\
n=527\end{array}$ \\
\hline \multicolumn{3}{|l|}{ Stratified by fetal growth status ${ }^{b}$} \\
\hline Not small for gestational age & $\begin{array}{l}0.2(-0.1,0.4) \\
n=542\end{array}$ & $\begin{array}{c}-0.1(-0.3,0.2) \\
n=540\end{array}$ \\
\hline Small for gestational age & $\begin{array}{c}-0.8(-1.7,0.0), \\
n=49\end{array}$ & $\begin{array}{c}-1.0(-2.1,-0.0) \\
n=49\end{array}$ \\
\hline \multicolumn{3}{|l|}{ Stratified by gestational age ${ }^{b}$} \\
\hline Gestational age 29 to $<33 \mathrm{wk}$ & $\begin{array}{c}\mathbf{0 . 3}(\mathbf{0 . 1}, \mathbf{0 . 6}) \\
n=349\end{array}$ & $\begin{array}{c}-0.01(-0.3,0.2) \\
n=348\end{array}$ \\
\hline Gestational age $<29$ wk & $\begin{array}{c}-0.4(-0.9,0.1) \\
n=180\end{array}$ & $\begin{array}{c}-\mathbf{0 . 5}(-\mathbf{1 . 0},-\mathbf{0 . 0 3}) \\
n=179\end{array}$ \\
\hline \multicolumn{3}{|l|}{ Stratified by sex ${ }^{b}$} \\
\hline Female & $\begin{array}{c}-0.1(-0.5,0.3), \\
n=251\end{array}$ & $\begin{array}{c}-0.3(-0.7,0.01) \\
n=249\end{array}$ \\
\hline Male & $\begin{array}{c}0.2(-0.2,0.5) \\
n=278\end{array}$ & $\begin{array}{c}-0.01(-0.3,0.3) \\
\quad n=278\end{array}$ \\
\hline \multicolumn{3}{|l|}{ Stratified by DHA status ${ }^{\mathrm{b}}$} \\
\hline Standard & $\begin{array}{c}0.1(-0.3,0.5) \\
n=274\end{array}$ & $\begin{array}{c}-0.2(-0.6,0.1) \\
n=273\end{array}$ \\
\hline High & $\begin{array}{c}0.0(-0.3,0.3) \\
n=255\end{array}$ & $\begin{array}{c}-0.2(-0.4,0.1) \\
n=254\end{array}$ \\
\hline
\end{tabular}

Bayley-II, Bayley Scales of Infant Development, 2nd Edition; DHA, docosahexaenoic acid. aEstimates adjusted for age, birthweight percentile, gestational age, sex, plurality, chronic lung disease, necrotizing enterocolitis, antenatal steroids, sepsis, postnatal steroids, Clinical Risk Index for Babies score, intraventricular hemorrhage grade 3 or 4, retinopathy of prematurity, maternal age, maternal and paternal education, maternal smoking during pregnancy, number of children and adults living at home, maternal and paternal occupation, Home Screening Questionnaire score, and solid food introduction at 4 mo.

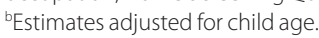

Bold indicates statistically significant results.

composition and therefore could not report nutrient intakes. Future studies should carefully consider the timing of exposure to human milk in relation to brain development, as well as the specific nutritional needs of preterm infants both during and after the neonatal hospitalization.

Strengths of our study include a large, contemporary, multicenter cohort and the prospective, detailed data collection on the volume of human milk intake during the neonatal hospitalization. We also had data on continued human milk intake after discharge, although not as detailed as the measured intake volume recorded in the hospital. We saw little difference in estimates with or without adjustment for many potential confounders; our null results are not likely to be explained by residual confounding. Subgroup analyses were based on a priori hypotheses, but given the small sample size within subgroups, we acknowledge the possibility of chance findings. Our study population comprised infants enrolled in a randomized, controlled trial whose families were mostly well educated and Caucasian, which may have reduced confounding by socioeconomic status, but may also limit generalizability. Further, in higher socioeconomic status groups, a benefit of human milk intake may be overwhelmed by other positive environmental factors, whereas a positive impact on neurodevelopment may be greater in lower socioeconomic groups. The Bayley-II is a gold standard neurodevelopmental test, but limited in its ability to predict future abilities with high precision (25).

\section{Conclusion}

We did not find substantial associations of human milk intake during the neonatal hospitalization with neurodevelopmental outcomes at 18 mo corrected age.

\section{METHODS \\ Participants}

We performed an observational secondary analysis using data from the DHA for Improvement of Neurodevelopmental Outcome (DINO) randomized trial (20). Infants born $\leq 33$ wk gestation were enrolled from April 2001 to October 2005 in five Australian perinatal centers. Exclusion criteria were major congenital anomalies, multiple births in which not all infants were eligible, and enrollment in other trials of fatty acid supplementation. The DINO study randomized infants to high ( $1 \%$ of total fatty acids) vs. standard ( $\sim 0.3 \%)$ DHA by supplementing their lactating mothers with DHA-rich tuna oil capsules or placebo and, if required, feeding preterm formula with high vs. standard DHA content. The intervention continued until term equivalent (40 wk postmenstrual age). Additional human milk fortification was standard practice (26) and provided at the discretion of the clinical team. All human milk fed to infants was their own mother's milk; donor breast milk was not used during the study period. Infants were assessed at term equivalent and at 4, 12, and 18 mo corrected age. The primary outcome for the DINO study was the Bayley-II at 18 mo corrected age. DINO found no difference in Bayley-II scores between randomized groups overall, but higher MDI scores in girls randomized to the high DHA diet (20).

For this secondary analysis, we combined all participants into one cohort. Participant flow is detailed in the original publication (20). Briefly, of the 657 original DINO participants, $616(94 \%)$ completed follow-up at 18 mo. Of those, two did not cooperate with testing, so Bayley scores were unavailable. Two were not tested due to severe impairments (one with vision impairment and one with multiple medical problems and global developmental delay). One additional child was excluded because the Bayley-III rather than the Bayley-II was administered in error. Thus, in this secondary analysis, we included 611 infants, representing $93 \%$ of the original cohort. Institutional review boards of each participating center (Women's and Children's Hospital, Adelaide, South Australia; Flinders Medical Centre, Adelaide, South Australia; Royal Women's Hospital, Melbourne, Victoria; Royal Brisbane and Women's Hospital, Brisbane, Queensland; King Edward Memorial Hospital, Perth, Western Australia) approved the original study and parents provided informed consent for participation. The institutional review boards of the coordinating center (Women's and Children's Health Network, Adelaide, Australia) and Boston Children's Hospital approved this secondary analysis.

\section{Main Exposures and Outcomes}

Human milk intake volume and duration. DINO study staff recorded all nutritional intake for each participating infant $1 \mathrm{~d} / \mathrm{wk}$ from birth to hospital discharge, including the volume of human milk in milliliters. It is possible to quantify the actual volume of milk ingested by hospitalized preterm infants because clinical staff administer most feedings via feeding tube or specialized bottle, in contrast to infants who directly breastfeed in whom the volume of milk intake is typically unknown. Using these data collected each week on human milk intake (ml per day) and the infant's body weight assessed in kilograms 
on the same day as the feeding data were collected, we calculated the mean $\mathrm{ml} / \mathrm{kg} / \mathrm{d}$ of human milk ingested over the course of each infant's neonatal hospitalization. We were not able to account for breast milk ingested when infants were put to breast.

At follow-up visits after hospital discharge (at term equivalent, 4, 12 , and 18 mo corrected age), study staff asked mothers questions about their infant's feeding to elicit the baby's main source of milk (only breast milk, both breast milk and formula, only formula); the extent of breastfeeding (exclusively breastfed, breastfed with $\geq 1$ bottle of formula per day; exclusively formula fed); and, if the mother had stopped breastfeeding since the last visit, on which date she stopped. We calculated the total duration of human milk intake (including both direct breastfeeding and other breast milk, e.g., by feeding tube or bottle), by combining the duration of human milk intake during the neonatal hospitalization with information about duration reported by the mother at the research follow-up visits. Maternal report of breastfeeding duration is valid, particularly when recall occurs over a short period of time (27) as in our study, although we were not able to quantify the actual volume of breast milk ingested after neonatal discharge.

Neurodevelopment. A trained psychologist or supervised psychology graduate student administered the Bayley-II when infants were 18 mo corrected age. Although all evaluators were trained in administration of the Bayley II, the interrater reliability was not assessed. The Bayley-II subscales are the MDI, which measures nonverbal and verbal cognition, and the PDI, which measures fine and gross motor skills. Both are scaled to a mean of 100 with SD of 15 . Scaled scores were for the child's corrected age (age from term equivalent, which is $40 \mathrm{wk}$ postmenstrual age). The range of possible scores is $50-150$ points. Six children $(<1 \%$ of cohort) scoring $<50$ on the MDI and 24 children ( $4 \%$ of cohort) scoring $<50$ on the PDI were assigned a score of 45 on that scale, consistent with scoring procedures employed for the primary study (20). Of those, 12 children were classified as having probable or definite cerebral palsy and 1 had visual impairment. One additional child had hearing impairment.

Covariates. DINO study staff gathered data from the infant medical record about gestational age, birth weight and length, sex, plurality, maternal age, diagnoses (chronic lung disease defined as requiring supplemental oxygen at $36 \mathrm{wk}$ postmenstrual age, necrotizing enterocolitis, sepsis, intraventricular hemorrhage grade 3 or 4 , retinopathy of prematurity), Clinical Risk Index for Babies score (28), and exposure to antenatal and postnatal steroids. At study enrollment, mothers were interviewed about smoking in pregnancy, education and occupation of both parents, and the number of people living at home. Introduction to solid foods was assessed at 4 mo. The Home Screening Questionnaire (29) measures aspects of the child's environment that contribute to cognitive development and was completed at the 18 -mo visit. Infants were weighed and measured by trained DINO study staff weekly during the neonatal hospitalization. Weight was measured to the nearest $5 \mathrm{~g}$ on a calibrated electronic scale. Length was measured to the nearest $0.1 \mathrm{~cm}$ using a recumbent length board. We calculated BMI $\left(\mathrm{kg} / \mathrm{m}^{2}\right)$ at birth and discharge, and the rate of change in BMI $\left(\mathrm{kg} / \mathrm{m}^{2} / \mathrm{wk}\right)$ and length $(\mathrm{cm} / \mathrm{wk})$ from birth to discharge.

\section{Statistical Analysis}

We estimated associations of human milk intake during the neonatal hospitalization $(\mathrm{ml} / \mathrm{kg} / \mathrm{d})$ and of total duration of human milk intake (months) with Bayley-II scores, using multivariable linear regression. We adjusted for child's corrected age at assessment (Model 0) and additionally adjusting for potential confounders including birth characteristics (birth weight percentile (30), gestational age, sex, plurality); neonatal health (diagnoses, antenatal and postnatal steroids, Clinical Risk Index for Babies score); and sociodemographic variables (maternal age, maternal and paternal education and occupation, maternal smoking, number of people living at home, and Home Screening Questionnaire score) (Model 1). In separate models (Model 2), we adjusted for BMI gain and linear growth to test the a priori hypothesis that poorer growth in human milk-fed infants was a negative confounder, such that adjustment for growth (to "remove" the adverse effect of human milk on growth) would strengthen associations. In analyses of total duration of human milk intake, we additionally adjusted for solid food intake at 4 mo (yes vs. no). Because $34 \%$ of participants were multiples, we used generalized estimating equations to account for clustering. We used least square means to estimate the adjusted mean Bayley-II scores (95\% CI) in each quartile of human milk intake in the neonatal hospitalization.

We performed separate analyses stratified by fetal growth status (SGA (birth weight percentile $(30)<10$ ) or non-SGA), gestational age $(<29$ wk or $29-33 \mathrm{wk})$, and sex. Because the DINO study was originally a randomized trial of DHA supplementation, we also stratified by high or standard DHA and calculated an interaction term. We used SAS 9.3 (SAS Institute, Cary, NC) for all analyses.

\section{STATEMENT OF FINANCIAL SUPPORT}

The trial on which this project was based (DHA for Improvement of Neurodevelopmental Outcomes) was supported by a 5 year project grant from the Australian National Health and Medical Research Council (NHMRC), ID 250322. The contents of the published material are solely the responsibility of the authors and do not reflect the views of the NHMRC. M.B.B. was supported by the National Institutes of Health (K23 DK83817). C.T.C. is supported through a MS McLeod Postdoctoral Research Fellowship (MS McLeod Research Fund, Women's and Children's Hospital Research Foundation). NHMRC Fellowships support R.A.G. (Senior Principal Research Fellow APP1046207) and M.M. (Principal Research Fellow APP1061704). The study sponsors had no role in the study design, data collection, analysis, or interpretation, manuscript writing, or decision to submit the manuscript.

Disclosure: Treatment and placebo capsules for the trial were donated by Clover Corporation and infant formula was donated by Mead Johnson Nutrition and Nutricia Australasia. M.M. serves on scientific advisory boards for Nestle, Fonterra, and Nutricia; R.A.G. serves on a scientific advisory board for Fonterra. The associated honoraria for M.M. and R.A.G. are paid to their institutions to support conference travel and continuing education for postgraduate students and early career researchers. M.B.B. is the principal investigator for a grant from Miris $A B$ to test the validity of a bedside human milk analyzer. No other disclosures were reported. No honorarium, grant, or other form of payment was given to anyone to produce the manuscript.

\section{REFERENCES}

1. Bhutta AT, Cleves MA, Casey PH, Cradock MM, Anand KJ. Cognitive and behavioral outcomes of school-aged children who were born preterm: a meta-analysis. JAMA 2002;288:728-37.

2. Outcomes CoUPBaAH. Preterm Birth: Causes, Consequences, and Prevention. Washington, DC: The National Academies Press, 2007.

3. Hill JL, Brooks-Gunn J, Waldfogel J. Sustained effects of high participation in an early intervention for low-birth-weight premature infants. Dev Psychol 2003;39:730-44.

4. Rouse DJ, Gibbins KJ. Magnesium sulfate for cerebral palsy prevention. Semin Perinatol 2013;37:414-6.

5. Schmidt B, Roberts RS, Davis P, et al.; Caffeine for Apnea of Prematurity Trial Group. Long-term effects of caffeine therapy for apnea of prematurity. N Engl J Med 2007;357:1893-902.

6. Jain A, Concato J, Leventhal JM. How good is the evidence linking breastfeeding and intelligence? Pediatrics 2002;109:1044-53.

7. Anderson JW, Johnstone BM, Remley DT. Breast-feeding and cognitive development: a meta-analysis. Am J Clin Nutr 1999;70:525-35.

8. Drane DL, Logemann JA. A critical evaluation of the evidence on the association between type of infant feeding and cognitive development. Paediatr Perinat Epidemiol 2000;14:349-56.

9. Belfort MB, Rifas-Shiman SL, Kleinman KP, et al. Infant feeding and childhood cognition at ages 3 and 7 years: effects of breastfeeding duration and exclusivity. JAMA Pediatr 2013;167:836-44.

10. Brion MJ, Lawlor DA, Matijasevich A, et al. What are the causal effects of breastfeeding on IQ, obesity and blood pressure? Evidence from comparing high-income with middle-income cohorts. Int J Epidemiol 2011;40:670-80.

11. Kramer MS, Aboud F, Mironova E, et al.; Promotion of Breastfeeding Intervention Trial (PROBIT) Study Group. Breastfeeding and child cognitive development: new evidence from a large randomized trial. Arch Gen Psychiatry 2008;65:578-84. 


\section{Articles | Jacobi-Polishook et al.}

12. Kleinman RE, ed. Pediatric Nutrition Handbook. 6th edn. Elk Grove Village, IL: American Academy of Pediatrics; 2009.

13. Vohr BR, Poindexter BB, Dusick AM, et al.; NICHD Neonatal Research Network. Beneficial effects of breast milk in the neonatal intensive care unit on the developmental outcome of extremely low birth weight infants at 18 months of age. Pediatrics 2006;118:e115-23.

14. Rozé JC, Darmaun D, Boquien CY, et al. The apparent breastfeeding paradox in very preterm infants: relationship between breast feeding, early weight gain and neurodevelopment based on results from two cohorts, EPIPAGE and LIFT. BMJ Open 2012;2:e000834.

15. Quigley MA, Hockley C, Carson C, Kelly Y, Renfrew MJ, Sacker A. Breastfeeding is associated with improved child cognitive development: a population-based cohort study. J Pediatr 2012;160:25-32.

16. O'Connor DL, Jacobs J, Hall R, et al. Growth and development of premature infants fed predominantly human milk, predominantly premature infant formula, or a combination of human milk and premature formula. J Pediatr Gastroenterol Nutr 2003;37:437-46.

17. Furman L, Wilson-Costello D, Friedman H, Taylor HG, Minich N, Hack M. The effect of neonatal maternal milk feeding on the neurodevelopmental outcome of very low birth weight infants. J Dev Behav Pediatr 2004;25:247-53.

18. Pinelli J, Saigal S, Atkinson SA. Effect of breastmilk consumption on neurodevelopmental outcomes at 6 and 12 months of age in VLBW infants. Adv Neonatal Care 2003;3:76-87.

19. Koo W, Tank S, Martin S, Shi R. Human milk and neurodevelopment in children with very low birth weight: a systematic review. Nutr J 2014;13:94.

20. Makrides M, Gibson RA, McPhee AJ, et al. Neurodevelopmental outcomes of preterm infants fed high-dose docosahexaenoic acid: a randomized controlled trial. JAMA 2009;301:175-82.
21. Bellinger DC. What is an adverse effect? A possible resolution of clinical and epidemiological perspectives on neurobehavioral toxicity. Environ Res 2004;95:394-405.

22. Ip S, Chung M, Raman G, et al. Breastfeeding and maternal and infant health outcomes in developed countries. Evid Rep Technol Assess (Full Rep) 2007:1-186.

23. Hüppi PS, Warfield S, Kikinis R, et al. Quantitative magnetic resonance imaging of brain development in premature and mature newborns. Ann Neurol 1998;43:224-35.

24. Belfort MB, Rifas-Shiman SL, Sullivan T, et al. Infant growth before and after term: effects on neurodevelopment in preterm infants. Pediatrics 2011;128:e899-906.

25. Hack M, Taylor HG, Drotar D, et al. Poor predictive validity of the Bayley Scales of Infant Development for cognitive function of extremely low birth weight children at school age. Pediatrics 2005;116:333-41.

26. Koletzko B, Poindexter B, Uauy R (eds). Nutritional Care of Preterm Infants: Scientific Basis and Practical Considerations, 3rd edition. Basel: Karger Publishers, 2014.

27. Li R, Scanlon KS, Serdula MK. The validity and reliability of maternal recall of breastfeeding practice. Nutr Rev 2005;63:103-10.

28. The CRIB (clinical risk index for babies) score: a tool for assessing initial neonatal risk and comparing performance of neonatal intensive care units. The International Neonatal Network. Lancet 1993;342:193-8.

29. Frankenburg WK, Coons CE. Home Screening Questionnaire: its validity in assessing home environment. J Pediatr 1986;108:624-6.

30. Oken E, Kleinman KP, Rich-Edwards J, Gillman MW. A nearly continuous measure of birth weight for gestational age using a United States national reference. BMC Pediatr 2003;3:6. 